\title{
Burden of Asymptomatic Bacteriuria Amongst Nigerian Pregnant Women: A Protocol for Systematic Review and Meta-Analysis
}

\section{Daniel N Onwusulu}

Nnamdi Azikiwe University

Helen Chioma Okoye

UNTH: University of Nigeria Teaching Hospital

Emmanuel 0 Nna ( $\nabla$ e.nna@themping.org )

The Molecular Pathology Institute, Enugu https://orcid.org/0000-0001-6791-2336

\section{Samuel Onuka}

Federal Medical Centre, Umuahia

Amaka Obiageli Nnamani

UNTH: University of Nigeria Teaching Hospital

\section{Richard Chinaza Ikeagwulonu}

Alex Ekwueme Federal University Teaching Hospital Abakaliki

Augustine Nwakuche Duru

UNTH: University of Nigeria Teaching Hospital

Uzoma Vivian Asiegbu

Alex Ekwueme Federal University Teaching Hospital Abakaliki

Dorathy Chinwe Obu

Alex Ekwueme Federal University Teaching Hospital Abakaliki

Ngozika Veronica Okoye

National Center for Natural Products Research

\section{Bamgboye M Afolabi}

Health, Environment and Developmental Foundation

Oluyemi Oluwatosin Akanni

FNPH: Federal Neuro Psychiatric Hospital,Benin

Dorothy Omono Esangbedo

Providence Hospital Ikoyi Lagos

\section{Yunusa Garba}

Usmanu Danfodiyo University College of Health Sciences

\section{Chinonyelum Thecla Ezeonu}

Alex Ekwueme Federal University Teaching Hospital Abakaliki

\section{Motunrayo Coker}


UCH: University College Hospital Ibadan

\section{Protocol}

Keywords: Asymptomatic bacteriuria, Screening, Pregnancy, Risk factors, Pregnancy outcomes, Nigeria

Posted Date: January 19th, 2021

DOl: https://doi.org/10.21203/rs.3.rs-148324/v1

License: (9) This work is licensed under a Creative Commons Attribution 4.0 International License. Read Full License 


\section{Abstract}

\section{Background}

Asymptomatic bacteriuria can be a cause of adverse pregnancy and neonatal outcomes if undetected and untreated. Pregnant women are usually routinely screened with urine cultures at antenatal booking. However, the exact burden of asymptomatic bacteriuria in Nigeria is unknown. Our protocol is aimed at determining the pooled prevalence of asymptomatic bacteriuria amongst Nigerian pregnant women as well as the associated risk factors and pregnancy outcomes.

Methods

Nine databases: PubMed, African Journal Online, Google Scholar, Cochrane Library, CINAHL, Embase, ResearchGate, Scopus, and Web of Science will be searched using a search strategy that is developed by combinations of MeSH terms, keywords, text words, and entry terms. Only observational studies published or retrievable in the English Language will be included. Studies must be conducted in Nigeria. The primary measurable outcome of this study is the prevalence of asymptomatic bacteriuria in pregnant women. Identified studies will be screened, selected, and deduplicated in DistillerSR. Data items will be extracted into predefined forms in the DistillerSR. Reports including Prisma flow chart, quality scores, risk of bias, and study outcomes will be generated in DistillerSR. Extracted data items will be exported into the Comprehensive Meta-analysis Software version 3 for quantitative analysis. Methodological, clinical, and statistical heterogeneity will be assessed for all the studies. Publication bias will be assessed using Funnel plots. There will be a subgroup analysis of pooled prevalence using categorical variables. The primary outcome will be expressed in pooled prevalence, standard error, variance, and $95 \% \mathrm{Cl}$ of variance. Quantitative risk factors and pregnancy outcomes will be used used for meta-regression. The reporting of the systematic review and meta-analysis will be according to PRISMA 2015 Statement.

\section{Discussion}

The pooled prevalence of asymptomatic bacteriuria in Nigeria will be examined in relation to associated risk factors and pregnancy outcomes. The study will be published in a peer-reviewed scientific journal.

Trial Registration Number

This protocol is registered with the Prospective Register of Systematic Reviews (PROSPERO) with registration number CRD42020213810

\section{Background}

Asymptomatic bacteriuria is significant bacterial colonization $\left(10^{5}\right.$ colony-forming units $\left.(\mathrm{cfu}) / \mathrm{mL}\right)[1-5]$ of urine and urinary tract but without any of the symptoms of infections. Studies have shown variations in the incidence in pregnancy which is reported to range from $2.0 \%$ to as high as $21.0 \%[1,2,6,7]$. If not treated, it may progress to acute pyelonephritis in about $30 \%$ of cases [8]. The resulting urosepsis has 
been associated with various adverse feto-maternal outcomes including anaemia in pregnancy, low birth weight, and preterm birth $[2,3,9,10]$.

The rates of asymptomatic bacteriuria may be the same in pregnant and non-pregnant women [11]. However, the course in the latter may be benign while the former will likely lead to a more adverse outcome if not treated. This is so because of the physiological changes in pregnancy that favour stasis in the urinary pathway. These changes include progesterone-induced decreased tone of the ureter, renal pelvis, and the bladder, pressure on the ureter, and displacement of the bladder from the pelvis into the abdomen by the gravid uterus [12].

The prevalence of asymptomatic bacteriuria in pregnant women is affected by many risk factors [13-15]. Some of the factors include socioeconomic status, history of recurrent urinary tract infection, diabetes mellitus, and anatomical abnormalities of the urinary tract, sickle cell disease, and retroviral disease [1415]. Sickle cell disease has been found to even double the risk in some studies [16]. To prevent the progression of asymptomatic bacteriuria, some developed countries adopt routine urine culture at the antenatal booking clinic as a standard form of care. This, however, is not done in Nigeria. Rather urine dipstick test is the norm; probably because the magnitude of the problem at the national level is unknown, likewise the attendant economic burden.

There have been some isolated studies, with no pool, to estimate the national burden [17-21]. To bridge this knowledge gap, we aim to carry out a systematic review and meta-analysis to qualitatively and quantitatively evaluate the prevalence, assess the associated risk factors and pregnancy outcomes of asymptomatic bacteriuria in pregnancy. The result of this study will likely be useful to health care policymakers seeking to standardize our medical care protocol to this vulnerable group and thereby reducing the associated adverse maternal and perinatal outcomes.

\section{Method And Design}

\section{Objective}

The main objective of this study is to determine the pooled prevalence of

asymptomatic bacteriuria in Nigerian pregnant women as well as the associated risk factors and pregnancy outcomes.

The specific objectives include:

1. To determine the pooled prevalence of asymptomatic bacteriuria amongst pregnant Nigerian women.

2. To evaluate the associated risk factors such as socioeconomic status, history of recurrent urinary tract infection (UTI), diabetes mellitus, and anatomical abnormalities of the urinary tract, sickle cell and retroviral diseases for asymptomatic bacteriuria in the pregnant Nigerian women. 
3. To assess pregnancy outcomes such as preterm birth, anemia, and pyelonephritis in asymptomatic bacteriuria

\section{Review Questions}

1. What is the pooled prevalence of asymptomatic bacteriuria amongst pregnant Nigerian women?

2. What are the frequencies of the risk factors associated with asymptomatic bacteriuria in pregnancy?

3. What are the frequencies of adverse feto-maternal outcomes associated with asymptomatic bacteriuria?

\section{Study Characteristics}

\section{a. Study Design:}

This is a protocol for systematic review and meta-analysis of observational studies that reported the prevalence of asymptomatic bacteriuria amongst pregnant women in Nigeria. There is no time restriction. Other types of study designs are excluded including interventional studies, comments, and editorials.

\section{b. Inclusion criteria}

1. Observational studies e.g., cross-sectional, case-control, cohort, retrospective, and historical cohort studies;

2. the study must report the prevalence of asymptomatic bacteriuria in pregnancy as a primary outcome.

3. the study must be retrievable in the English language.

\section{4. the study must be available in electronic databases.}

\section{c. Exclusion criteria}

1. Letters to editors, reviews, commentaries, and editorials.

2. Duplicate of same studies.

3. Studies with secondary but no primary outcome.

4. Studies on the prevalence of asymptomatic bacteriuria but not in pregnancy.

5. Interventional studies including randomized clinical trials and quasi-clinical trials.

6. Non-Nigerian studies or studies on Nigerians in the diaspora.

7. Grey literature will not be included.

\section{PICOs}

Participants are all pregnant Nigerian women with asymptomatic bacteriuria.

Intervention: there is no intervention. 
Comparator: there is no comparator.

Outcomes: the primary outcome is the proportion of asymptomatic bacteriuria in pregnant women in Nigeria. Secondary outcomes are: - a) frequencies of risk factors including recurrent UTI, SCD, HIV infection, parity, urinary tract abnormalities, urethral catheterization, and pyelonephritis; and b) pregnancy

outcomes will include the proportion of preterm delivery, intrauterine growth restriction, neonatal sepsis; and puerperal sepsis.

Effect size for the primary outcome is the prevalence

Effect size for secondary outcomes is prevalence except for categorical variables that serve as moderators.

\section{Information sources}

The search will employ sensitive topic-based strategies designed for each

database. The following databases will be searched: CINAHL, Embase, PubMed, Web of Science, Google scholar, African journals online (AJOL), Scopus,

ResearchGate, and Cochrane Library. Only observational studies that are conducted in Nigeria and retrievable in the English Language will be included.

\section{Search strategy}

The search strategy will include MeSH terms, text words, and entry terms. The

Search strategies used in databases are as shown in Table 1.

\section{Data Extraction and Management}

Three main tools will be used to manage data: DistillerSR, CMA software version 3 and Microsoft Excel.

a. Screening: Identified studies will be independently and blindly screened in pairs using the DistillerSR software at the following levels:

1. Level 1: study design: only observational studies will be included.

2. Level 2: screening of titles and abstracts of identified studies using search strategy.

3. Level 3: full texts will be screened using search strategy.

4. Level 4: Snowballing of articles to identify more relevant studies.

5. Level 5: Studies will be screened for primary and secondary outcomes. 
6. Level 6: Studies will be screened for risk of bias using NIH Quality assessment for observational studies.

Conflicts during screening will be resolved by a third reviewer, who serves as a tiebreaker.

b. Selection process: Studies will be selected based on study design, inclusion/exclusion criteria, and screening outcomes. Full-text articles will be obtained for all included studies. Primary outcomes must be reported in all eligible studies. Authors of eligible articles with missing data will be contacted by email and telephone. Depulication of eligible studies will be performed using the DistillerRS.

c. Data collection process: Extractable data item will be collected into predefined forms created in the DistillerSR. Extractable data items from eligible studies will include:

1. Surname of first author and year of publication

2. Proportion of asymptomatic bacteriuria in pregnant Nigerian women (prevalence)

3. Mean patient's age

4. Risk factors: recurrent UTI, SCD , HIV infection, parity, urinary tract abnormalities, urethral catheterization, and pyelonephritis

5. Pregnancy outcomes: the proportion of preterm delivery, intrauterine growth restriction, neonatal sepsis; and puerperal sepsis.

6. Method of detecting bacteriuria: dipstick, culture, and PCR

The effect size for primary outcome is prevalence. Effect size for most of the secondary outcomes is prevalence.

\section{Risk of bias}

The risk of bias in eligible studies will be accessed for the individual studies using the National Institute of Health $(\mathrm{NIH})$ Quality assessment tool for observational studies. This will be cross-checked with the Cochrane tool of risk of bias assessment for the strength of the body of evidence.

The following areas shall be assessed and any study with extreme bias will be

excluded following a consensus decision.

1. Method of testing and reporting at the outcome level

2. Reporting of study: whether proportion/ prevalence with confidence interval or number of cases / sample size are reported at the outcome level. Primary indexes from studies with similar design and report outcome will be converted to prevalence which is the primary effect size.

3. Heterogeneity will be assessed at the study level.

4. Publication bias will be assessed at the study level.

5. Sensitivity analysis will be done at the study level. 


\section{Assessment of Meta-bias}

To test for heterogeneity: Cochrane's $Q$ value and its $p$-value, $I^{2}, \rrbracket^{2}$ will be used. The effect size is the prevalence at a $95 \%$ Confidence Interval $(\mathrm{Cl}, 95 \%)$. As a rule of thumb, $\mathrm{I}^{2}$ values of less than $40 \%$ will be considered low heterogeneity while values $>40$ but $<75 \%$ will be considered moderate and values $>75 \%$ are high.

\section{Data synthesis:}

Both narrative synthesis and quantitative analysis will be performed.

All studies that report primary outcomes with or without secondary outcomes will be included for systematic review, with all measurable outcomes and sample size reported in a tabular format. Studies with primary indices that can be converted to prevalence will be converted in the CMA Software version 3 .

\section{Quantitative Analysis}

Quantitative data will include pooled prevalence, standard error, and $95 \% \mathrm{Cl}$. Both random and fixed effect models will be assessed, and the appropriate model will be taken based on the forest plots. Quantitative analysis will be done using the Comprehensive Meta-analysis CMA software version 3 .

\section{Further Analysis}

Subgroups analysis will be done using categorical risk factors and pregnancy outcomes as moderators. Meta-regression will be done with mean maternal age and parity. A cumulative meta-analysis will be performed to check for the trend in the prevalence of asymptomatic bacteriuria over the years.

\section{Presentation and Reporting of Results}

The study selection process will be summarized in a Prisma flow chart according to the PRISMA 2015 Statement and PRISMA-P Checklist [24,25]. A table of the search strategy in various databases will be presented. A list of included studies will be summarized in a table. Quantitative data: prevalence, standard error, $95 \% \mathrm{Cl}, \mathrm{P}$ values, relative weights assigned to studies, and heterogeneity tests will be reported in the forest plots. A table of quality scores and risk of bias of each eligible study will be presented. Forest and regression plots to show subgroup analysis and meta-regression respectively will be presented as well.

\section{Discussion}

The study will discuss the burden of asymptomatic bacteriuria in pregnant Nigerian women based on the pooled prevalence. It will examine the risk factors associated with asymptomatic bacteriuria in pregnancy in Nigeria as well as the pregnancy outcomes. The outcome of this study will impact on the method of detecting asymptomatic bacteriuria, wether dipstick testing is adequate enough or not compared to urine cultures. The findings of this study will inform choice of preventive measures to be recommended by 
policymakers. The strength of evidence for this study will be scored using the NIH Quality Assessment for Systematic Reviews and Meta-analysis. The final outcome will be published in a peer-reviewed scientific journal.

\section{Abbreviations}

AGCPN: Association for Good Clinical Practice in Nigeria

CINAHL: Cumulative index to Nursing and Allied Health literature

AJOL: African Journals online

UTI: Urinary tract infection

SCD: Sickle cell Disease

$\mathrm{NIH}$ : National Institute of Health

PCR: Polymerase chain reaction

PRISMA: Preferred Reporting Items for Systematic Review and Meta-analysis

PROSPERO: International Prospective Register of Systematic Reviews

\section{Declarations}

\section{Ethics and Dissemination}

Ethical approval will not be required, since this study will rely solely on the secondary source of data

Contributions: DO, EN, and HO conceived the project, DO, EN, HO, and AN designed the study, BA and IR did PubMed searches, screening and review; $\mathrm{HO}$ and DO did AJOL search, UA, MC, and NO did Embase and Scopus searches and review; SO, GO and AN did Google scholar and WebOS searches and DE and YG did searches and review for CINAHL database, CE and OA did searches on Cochrane Databasewhile $A D$ did review of Researchgate.

\section{Support and Funding}

Funding: Association for Good Clinical Practice in Nigeria (AGCPN)

Support: AGCPN for providing access to subscribed databases.

Guarantor of the Review: Dr Emmanuel Nna

Ethics approval and consent to participate: None 
Consent for publication: It is not applicable

Availability of data: All data from this study will be made public.

Competing interests: The authors declare no competing interest

Acknowledgments: Thanks to staff of AGCPN for helping with databases.

\section{References}

1. Rouse DJ, Andrews WW, Goldenberg RL, Owen J. Screening and treatment of asymptomatic bacteriuria of pregnancy to prevent pyelonephritis: A cost357 effectiveness and cost-benefit analysis. Obstet Gynecol. 1995;86(1):119-23.

2. Mangalgi S, Sajjan A. Asymptomatic bacteriuria in pregnancy. J Krishna Inst Med Sci Univ. 2018;7(3):35-42.

3. Littlewood JM. Asymptomatic Bacteriuria. Br Med J. 1969 Jan 12; 3 (5667): 416.

4. Brun JL, Fritel X, Aubard Y, Borghese B, Bourdel N, Chabbert-Buffet N, et al. Management of presumed benign ovarian tumors: Updated French guidelines. Eur J Obstet Gynecol Reprod Biol. 2014;183:528.

5. Musona-Rukweza J, Haruzivishe C, Gidiri FM, Nziramasanga P, Stray-Pedersen B. Asymptomatic Bacteriuria in Pregnancy: A Concept Analysis. J MicrobiolRes Rev. 2017;4(1):1-11.

6. Chou D, Tunçalp Ö, Firoz T, Barreix M, Filippi V, von Dadelszen P, et al. Constructing maternal morbidity - towards a standard tool to measure and monitor maternal health beyond mortality. BMC Pregnancy Childbirth. 2016 Dec 2;16(1):45.

7. Kasraeian M, Asadi N, Ghaffarpasand F. Prevalence of asymptomaticbacteriuria among pregnant women in Shiraz, Iran. Saudi Med J.2009;30(7):917-20.

8. Perera J, Randeniya C, Perera P, Gamhewage N, Jayalatharchchi R.Asymptomatic bacteriuria in pregnancy: prevalence, risk factors andcausative organisms. Sri Lankan J Infect Dis. 2012;2(1):42.

9. Sahni DS. Prevalence of Asymptomatic Bacteriuria in Pregnancy and Its Outcome. J Med Sci Clin Res. 2016;13033.

10. Prabhavathi V, Krishnamma B, Krishna Murthy G, Prasad DKV. Prevalence of asymptomatic bacteriuria among antenatal women and its effects on maternal and perinatal outcome in northern Andhra Pradesh population. International Journal of Advances in Medicine. 2018 Jan 18;5(1):17985.

11. Al Senani NS. Asymptomatic bacteriuria in pregnant women. Bahrain Med Bull. 2011;33(4):192.

12. Dafnis E, Sabatini S. The Effect of Pregnancy on Renal Function: Physiology and Pathophysiology. Am J Med Sci. 1992 Mar;303(3):184-205.

13. Lallar M, Haq A, Nandal R. Asymptomatic bacteriuria: predisposing factors and correlation with preterm labor in low resource settings. Int J Reprod Contraception, Obstet Gynecol. 2014;(January 
2014):403-8.

14. Main EK, Abreo A, McNulty J, Gilbert W, McNally C, Poeltler D, et al. Measuring severe maternal morbidity: 390 validation of potential measures. Am J Obstet Gynecol. 2016 May;214(5): 643.e1643.e10.

15. Byna P, Muvva N, Kolli S, Shaik M. A study of risk factors and consequences of asymptomatic bacteriuria in pregnant women and feto-maternal outcome. Int J Reprod Contraception, Obstet Gynecol. 2015;(September):1300-5.

16. Baill IC, Witter FR. Sickle trait and its association with birth weight and urinary tract infections in pregnancy. Int J Gynecol Obstet. 1990 Sep; 33(1): 19-21.

17. Aboderin A, Ako-Nai A, Zailani S, Ajayi A, Adedosu A. A Study Of Asymptomatic Bacteriuria In Pregnancy In Ile-Ife, Southwestern Nigeria. African J Clin Exp Microbiol. 2004 Sep 20; 5(3).

18. Oyagade $A$, Smith $S$, Famurewa $O$. Asymptomatic significant bacteriuria among pregnant women in Ado-Ekiti, Ekiti State Nigeria. African J Clin Exp Microbiol. 2004;5(1).

19. Urombo CT, Agboghoroma CO, Efetie ER. Asymptomatic Bacteriuria in pregnant women attending antenatal clinic in a tertiary hospital in Abuja, Nigeria. Trop J Obstet Gynaecol. 2015;32(1):27-33.

20. Omole - Ohonsi A, Nwokedi E. Asymptomatic Bacteriuria in Pregnancy in Kano, Nothern Nigeria. Niger Hosp Pract. 2009;2(4).

21. Ezeome IV, Ikeme AC, Okezie OA OE. Asymptomatic bacteriuria (ASB) in pregnant women in Enugu, Nigeria _ Tropical Journal of Obstetrics and Gynaecology. Trop J Obstet Gynaecol. 2006;23.4

22. Evidence Partners. DistillerSR [Internet]. Ottawa, Canada: Evidence Partners Incorporated; 2020. Available from: https://www.evidencepartners.com/

23. Borenstein M, Hedges L, Higgins J, Rothstein H. Comprehensive Meta-Analysis [Internet]. Englewood, NJ 2013: Biostat; 2020. Available from: https://www.meta-analysis.com/

24. Moher D, Shamseer L, Clarke M, Ghersi D, Liberati A, Petticrew M, et al. Preferred reporting items for systematic review and meta-analysis protocols (PRISMA-P) 2015 statement. Syst Rev. 2015 Jan 1;4:1.

25. Moher D, Liberati A, Tetzlaff J, Altman DG, The PRISMA Group. Preferred Reporting Items for Systematic Reviews and Meta-Analyses: The PRISMA Statement. PLOS Medicine. $2009 \mathrm{Jul}$ 21;6(7):e1000097.

\section{Tables}

Due to technical limitations, table 1 is only available as a download in the Supplemental Files section.

\section{Supplementary Files}

This is a list of supplementary files associated with this preprint. Click to download. 
- Table1SearchStrategyASB.pdf

- PRISMAPchecklistBMCASBFinal.docx 